\title{
Response to Letter to the Editor from Dr. Guilford
}

\author{
John P. Richie Jr. ${ }^{1} \cdot$ Joshua Muscat $^{2}$
}

Published online: 26 March 2015

(C) Springer-Verlag Berlin Heidelberg 2015

Dear Dr. Rowland,

Please accept our response to Dr. Frederick Guilford's comments of November 17, 2014, regarding our recent article which appeared in your Journal [1].

The main issue described by Dr. Guilford refers to a published paper [2] referenced in the discussion section of our paper (reference \#68). We cited that paper as an example of an in vitro study where intact GSH was shown to be more effective than $\mathrm{N}$-acetylcysteine in "restoring immune function in macrophages from HIV-infected individuals" [1]. Indeed, Dr. Guilford is correct in that the GSH preparation used in that study was a liposome encapsulated GSH obtained from his company as opposed to the non-encapsulated form used in our study. However, I would like to emphasize that our study was not designed to test the relative efficacy of different GSH preparations, including liposomal GSH, but rather to determine the impact of GSH supplementation alone on GSH levels in blood and exfoliated buccal cells.

We disagree with Dr. Guilford's assertion that GSH must be broken down prior to absorption into cells. While mechanisms are still under study, numerous GSH transporters have been identified in mammalian cells [3, 4]. Further, direct absorption has been reported in human and rodent cells as wells as in mice in vivo $[4,5]$. Liposomal encapsulation of GSH may prove an effective means of increasing GSH absorption, as suggested by the results of several in vitro studies as noted by Dr. Guilford. However, to our knowledge, data in humans are still lacking.

Thank you for the opportunity to respond to these comments.

Sincerely yours,

\section{References}

1. Richie JP et al (2015) Randomized controlled trial of oral glutathione supplementation on body stores of glutathione. Eur $\mathbf{J}$ Nutr 54:251-263

2. Morris D et al (2013) Glutathione supplementation improves macrophage functions in HIV. J Interf Cytokine Res Off J Int Soc Interf Cytokine Res 33:270-279

3. Kariya C et al (2007) A role for CFTR in the elevation of glutathione levels in the lung by oral glutathione administration. Am J Physiol Lung Cell Mol Physiol 292:L1590-L1597

4. Bachhawat AK et al (2013) Glutathione transporters. Biochim Biophys Acta 1830:3154-3164

5. Kovacs-Nolan J et al (2014) In Vitro and ex vivo uptake of glutathione (GSH) across the intestinal epithelium and fate of oral GSH after in vivo supplementation. J Agric Food Chem 62:9499-9506

This reply refers to the article available at doi:10.1007/s00394-015-0874-5.

John P. Richie Jr.

jrichie@psu.edu

1 Public Health Sciences and Pharmacology, Penn State University College of Medicine, Hershey, PA, USA

2 Public Health Sciences, Penn State University College of Medicine, Hershey, PA, USA 